Mohamed Naguib MB B CH MSC, Hesham Farag MB BCH FFARCS, Ravindra N. Joshi MD

\title{
Bilateral hydrothorax and hydromediastinum after a subclavian line insertion
}

\begin{abstract}
A 28-year-old male patient developed bilateral hydrothorax due to extravasation of fluid into the mediastinum from a subclavian line. The injection of radio-opaque dye through the central venous cannula confirmed spillage into the mediastinum. There was no direct communication between the central venous cannula and the pleural cavities. The hydrothorax appeared to develop as a result of a shift of fiuid from the mediastinum into the pleural cavities due to pressure differences in the two compartments. Bilateral chest tubes were inserted, the subclavian cannula was removed and the patient made a good recovery.
\end{abstract}

\section{Key words}

COMPLICATIONS; hydrothorax; vEINS: cannulation, subclavian, complications.

Since the introduction of central venous catheterization to clinical practice in $1945,{ }^{1}$ the technique has been widely used for the management of severely ill and injured patients. The subclavian route has gained popularity among anaesthetists because of easy access, reliability and catheter tolerance by conscious patients. The procedure is not without complications. Most reviews report complications in less than five per cent of cases, ${ }^{2}$ but in one series the incidence of fatal complications was 1.4 per cent. $^{3}$

The reported hazards of central venous catheterization include venous laceration, ${ }^{4}$ haematoma formation, ${ }^{5}$ arterial puncture, ${ }^{6}$ catheter embolism, ${ }^{7}$

From the Department of Anesthesiology, King Faisal University, King Fahd Hospital, P.O. Box 2208, A] Khobar 31952; Saudi Arabia; where correspondence should be addressed to Dr. Naguib.
Horner's Syndrome with vocal cord paralysis, ${ }^{8}$ pneumothorax, hydrothorax, ${ }^{9}$ haemothorax, subcutaneous emphysema, arteriovenous fistula, brachial plexus injury, air embolism, ${ }^{10}$ thoracic duct injury, " hydromediastinum, ${ }^{12}$ laceration of vertebral artery, ${ }^{13}$ thrombus formation, ${ }^{14}$ cardiac tamponade, ${ }^{15}$ tracheal puncture, ${ }^{16}$ and local and systemic infection. ${ }^{17}$

The occurrence of bilateral hydrothorax following unilateral subclavian catheterization has not been previously reported.

We report a patient who presented with bilateral hydrothorax following extravasation of the central venous line infusion into the mediastinum.

\section{Case report}

A 28-year-old male presented to the emergency room with a fractured pelvis, fractured left tibia and fibula and internal haemorrhage, after a road traffic accident. He was in shock with blood pressure of $9.3 / 6.6 \mathrm{kPa}(70 / 50 \mathrm{mmHg})$, and pulse rate of $145 /$ minute. After resuscitation, the patient was taken to the operating room for exploratory laparotomy under general anaesthesia, and the right internal iliac artery was ligated. During surgery, the anaesthetist found that the single intravenous line was inadequate to replace blood loss. He inserted a 14 gauge $8.3 \mathrm{~cm}$ angiocath into the left subclavian vein for fluid replacement. Three units of blood were transfused through the subclavian cannula during the operation. A chest $x$-ray taken postoperatively showed no abnormality. The patient was transferred in a stable condition, to the intensive care unit for observation. BP was $14.9 / 9.3 \mathrm{kPa}(112 / 70 \mathrm{mmHg})$ and heart rate $100 /$ minute.

Three hours later, he again became tachycardiac and hypotensive with a heart rate of $136 /$ minute and BP $12 / 9.3 \mathrm{kPa}(90 / 70 \mathrm{mmHg})$. The respiratory rate was $34 /$ minute. A diagnosis of hypovolemia was 


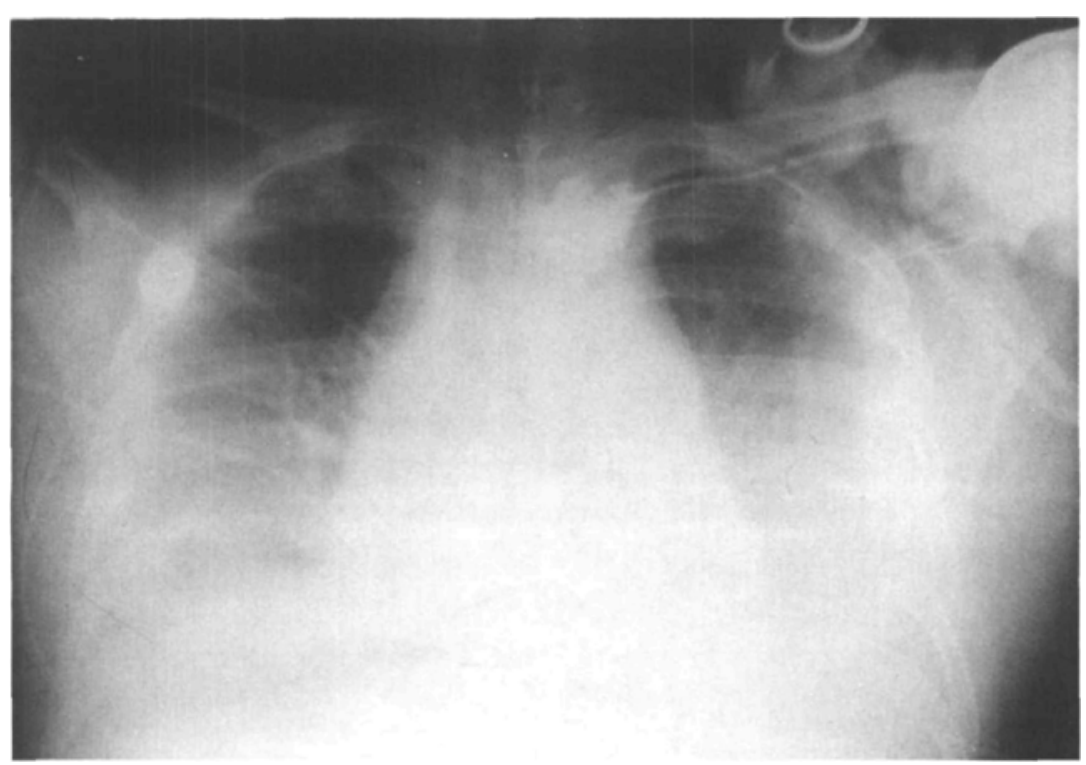

FIGURE Chest radiograph demonstrating extravasation of radio-opaque dye into mediastinum. Two ml of dye was injected into the subclavian cannula.

made. Three liters of "Isolyte E" with dextrose five per cent* were infused through the central venous line over five hours. The patient's condition deteriorated further. A chest $x$-ray at that time showed widening of the mediastinum. The surgeon planned to do aortic angiography to exclude rupture of the thoracic aorta. Extravasation from the central venous line was also considered. $2 \mathrm{ml}$ of radio-opaque dye was injected through the cannula and extravasation of the dye into the mediastinum was confirmed (Figure). The cannula was removed.

However, five hours later, the patient's condition deteriorated further. He became tachypnocic, tachycardic and hypotensive. Clinical examination and chest $x$-ray disclosed bilateral hydrothorax. Chest tubes were inserted bilaterally at the seventh intercostal space in the mid-axillary line. One and one-half litres of clear fluid was retrieved from cach thorax. The patient's condition imporved dramati-

*Composition of "Isolyte E" with five per cent dextrose: calories 180 per litre; osmolarity $565 \mathrm{mOsm} / \mathrm{litre} ; \mathrm{pH}$ 5.8; electrolytes in milliequivalents per litre: $\mathrm{Na}^{+} 140$, $\mathrm{K}^{+} 10, \mathrm{Ca}^{++}, \mathrm{Mg}^{++} 3, \mathrm{Cl}^{-} 103$, acetate 47 . cally and he was discharged from the intensive care unit 24 hours later.

The chemical analysis of the fluid from the chest tubes showed: Na $126 \mathrm{mmol} / \mathrm{litre}, \mathrm{K} 4.4 \mathrm{mmol}$ litre, $\mathrm{Cl} 100 \mathrm{mmol} /$ litre, $\mathrm{HCO}_{3} 21 \mathrm{mmol} / \mathrm{litre}, \mathrm{Ca}$ $1.4 \mathrm{mmol} /$ litre, $\mathrm{pH} 8.5$ and total protein $0.7 \mathrm{~g} /$ litre which was very similar to the IV fluid injected.

Three days later the patient had an orthopedic operation under general anaesthesia for intemal fixation of the fractured tibia and fibula. The anaesthetic and postoperative course were uneventful.

\section{Discussion}

Extravasation into the mediastinum from subclavian vein leakage is a well documented complication. ${ }^{12}$ Perforation of a vein with a trocar can occur during insertion of the central line or may occur hours or days after cannulation with a rigid cannula. Hydromediastinum and the delayed onset of symptoms can occur because of damage to a vein caused by the rigid cannula used in this case. This has been reported. ${ }^{15}$ It is suggested that the occurrence of bilateral hydrothorax may have been due to the shift 
of the extravasated fluid from the mediastinum through the thin mesothelium of the parietal pleurae, facilitated by the pressure differences between the two compartments. The delayed onset of symptoms could also be accounted for by changes in intravascular volume over time. Pericardial and pleural pressure increases are more effective in decreasing arterial blood pressure when hypovolemia is present than in hyper- or normovolemic patients.

The injection of contrast medium is a useful investigation for the diagnosis of extravasation or aberrant placement of a CVP catheter. ${ }^{15}$

Meticulous technique, awareness of the complications and close observation of the patient are necessary in the management of a central venous line.

\section{Acknowledgements}

The authors wish to thank Professor Richard I. Bodman for reviewing this manuscript and $\mathrm{Mr}$. Emmanuel I. Lapak for his secretarial assistance.

\section{References}

1 Myers $L$. Intravenous catheterization. Am J Nursing 1945; 45: 930.

2 Edwards H, King TC. Cardiac tamponade from central venous catheters. Arch Surg 1982; 117: 965-7.

3 Adar R, Mozes M. Fatal complications of central venous catheters. Br Med J 1971; 3: 746.

4 Galbert MW, Kay JE. Perforation of the right innominate vein by central venous polyethylene catheter. Br J Anaesth 1971; 43: 713-4.

5 Brown CS, Wallace CT. Chronic hematoma - a complication of percutaneous catheterization of the internal jugular vein. Anesthesiology 1976; 45: 368-9.

6 Korshin J, Klauber PV, Christensen V, Skovsted $P$. Percutaneous catheterization of the internal jugular vein. Acta Anaesthesiol Scand 1978; 67 (Suppl.): 27-33.

7 Wellman $K F$, Reinhard A, Salazar EP. Polyethylene catheter embolism. Circulation 1968; 37: 380-92.

8 Davis $P$, Watson $D$. Horner's syndrome and vocal cord paralysis as a complication percutaneous in ternal jugular vein catheterization in adults. Anaesthesia 1982; 37: 587-8.

9 Holt S, Myerscough E. Pneumothorax and hydro- thorax after subclavian vein cannulation. Postgrad Med J 1977; 53: 226-7.

10 Latimer $R D$. Central venous catheterization. $\mathrm{Br} \mathrm{J}$ Hosp Med 1971; 5: 369.

11 Burri C, Henkemeyer $H C$. Review of the use of 3,241 Caval catheters; in Wilkinson Parenteral Nutrition 1972; pp. 234-41 (Churchill, Livingstone, London)

12 Arbitman $M$, Kart $B H$. Hydromediastinum after aberrant central venous catheter placement. Crit Care Med 1979; 7: 27-9.

13 Morgan RNW, Morrel DF. Internal jugular catheterization. A review of a potentially lethal hazard. Anaesthesia 1981; 36: 512-7.

14 Hecker JF, Fish GC, Farrel PC. Measurement of thrombous formation on intravenous catheters. Anaesth Intensive Care 1976; 4: 225-31.

15 Defalque RJ, Campbell C. Cardiac tamponade from central venous catheters. Anesthesiology 1979; 50: 249-52.

16 Konichesky S, Soroker D. Tracheal puncture. A complication of percutaneous internal jugular vein cannulation. Anaesthesia 1983; 38; 572-4.

17 Bently $D W$. Lepper $M H$. Septicemia related to indwelling venous catheter. JAMA 1968; 206:

1749-52.

\section{Résumé}

Un patient de 28 ans a développé un hydrothorax bilatéral, par extravasation dans le médiastin, suite à l'insertion de cathéter dans la veine sous-clavière. L'injection de produit radio-opaque par la canule veineuse centrale a démontré la fuite dans le médiastin. Il $n^{t} y$ avait aucune communication directe entre la canule veineuse centrale et les cavités pleurales. L'hydrothorax s'est développé comme résultat d' un transfert de liquide du médiastin vers les cavités pleurales à cause des differences de pression dans les deux compartiments. Les tubes de drainage thoracique bilatéraux ont été insérés, la canule sous-clavière a été enlevée et le patient fut conduit vers la guérison. 